\title{
EVALUACIJA KORNIŠSIŠEROVOG VAR MODELA NA TRŽIŠTU KAPITALA U HRVATSKOJ U PERIODU OD 2005. DO 2015. GODINE
}

\author{
Ivica Terzić1, \\ Marko Milojević, \\ Dragan Miletić2
}

\author{
${ }^{1}$ Univerzitet Singidunum, \\ Beograd, Srbija \\ ${ }^{2}$ Fondacija "Centar za mlade talente" \\ Novi Sad, Srbija
}

\begin{abstract}
Apstrakt:
U poslednje dve decenije VaR je postao standard za procenu tržišnog rizika u finansijskoj industriji. Iako su razvijeni razni pristupi za procenu rizične vrednosti, finansijske institucije se i dalje oslanjaju na standardne VaR pristupe, kao što su istorijska simulacija, varijansa-kovarijansa model i Montekarlo simulacija. Poslednja kriza je pokazala da ovi modeli nisu mogli predvideti sa velikom pouzdanošću crne labudove na finansijkom tržištu. Stoga, cilj ovog rada je da uvedemo Korniš-Fišerovu (CFVaR) aproksimaciju za utvrdjivanje VaR-a i empirijski izvršimo backtesting i komparaciju CFVaR procena sa nekim od standardnih VaR pristupa. Istraživanje je sprovedeno na primeru hrvatskog tržišta kapitala u periodu od 2005. do 2015. godine. Backtest-ovi Kupika i Kristofersena ukazuju da standardni VaR modeli u značajnoj meri potcenjuju izloženost tržišnom riziku, dok za isti posmatrani period CFVaR daje zadovoljavajuće procene tržišnog rizika. Rezultati istraživanja treba da posluže svim učesnicima na finansijskom tržištu kao korisne smernice za unapređenje sistema upravljanja rizicima u savremenim uslovima poslovanja.
\end{abstract}

Ključne reči:

tržišni rizik, istorijska simulacija, linearni VaR, Crobex, Korniš-Fišer VaR.

\section{UVOD}

Počevši od pionirskog rada Harija Markovica iz 50-ih godina prošlog veka, sofisticirane statističke i matematičke tehnike sve više nalaze primenu u finansijama i upravljanju rizicima.

Kvantitativna analiza rizika igra važnu ulogu u proceni rizika koji nas okružuju prilikom donošenja odluka o investiranju. Merenje rizika preokupira učesnike finansijskog tržišta od početka finansijske istorije i predstavlja klasičan problem u finansijama. Brza globalizacija finansijskih tržišta kao i nedavna finansijska kriza primorale su risk menadžere, kao i regulatorna tela, da prepoznaju sve veći značaj upravljanja rizikom i potrebu za preciznim merama rizika. Finansijski risk menadžment i metode adekvatnog merenja rizika dospele su u žižu interesovanja više nego ikada pre u današnjoj turbulentnoj ekonomskoj klimi, kako među praktičarima, tako i u akademskim krugovima. U tom smislu, adekvatna analiza i primena savremenih metoda merenja rizika dobija sve više na značaju. Jedna od njih je VaR metoda, koja je razvijena od strane J. P. Morgana početkom devedesetih godina prošlog veka. VaR je jedinstvena, sumarna, statistička mera mogućih gubitaka u vrednosti portfolija (Terzić, 2014).

VaR je postao popularna metoda za procenu izloženosti tržišnom riziku i u praksi se ustalilo nekoliko standardnih pristupa za njegovo izračunavanje, što je podržano od strane Bazelskog komiteta za superviziju banaka. Međutim, većina VaR pristupa je zasnovana na određenim pretpostavkama koje podrazumevaju tzv. normalne tržišne okolnosti. U uslovima relativno stabilnog tržišta, VaR modeli daju zadovoljavajuće procene rizika. Međutim, poslednja svetska ekonomska kriza je potvrdila da standardni VaR modeli nisu mogli da predvide tržišne šokove koji su nam se dogodili. Upravo to je bio jedan od ključnih razloga da se revidira čitav set postojećih modela u industriji upravljanja finansijskim rizicima koji se pretežno zasnivaju na aproksimaciji normalne raspodele prinosa finansijske aktive. 
Ovaj rad se fokusira na istraživanju problema merenja tržišnog rizika uz primenu modifikovanog VaR metoda zasnovanog na Korniš-Fišerovoj aproksimaciji finansijskih tržišta u tranziciji. Analiza je sprovedena na hrvatskom tržištu kapitala, zbog određenih prednosti koje poseduje (npr. visoka likvidnost, dubina i širina tržišta ) u odnosu na ostale zemlje iz okruženja. Dakle, cilj istraživanja je da uvedemo alternativne raspodele prinosa finansijske aktive i napravimo pomak u odnosu na pristup koji koristi pretpostavku normalne raspodele, kako bismo poboljšali procenu izloženosti tržišnom riziku. Ideja je da dokumentujemo ključne karakteristike prinosa na rizičnu aktivu hrvatskog finansijskog tržišta i da na osnovu toga konstruišemo prilagodljiv VaR model koji će uspešno moći da obuhvati te karakteristike. Ključni doprinos našeg rada ogleda se u razvijanju i preporuci novog VaR modela koji je pogodan za hrvatsko tržište kapitala.

U radu analiziramo jednostavnu Korniš-Fišerovu aproksimaciju u linearni VaR model koji pretpostavlja raspodelu koja nije normalna. Ovaj alternativni način izračunavanja rizične vrednosti finansijske aktive ima određene prednosti u odnosu na druge VaR pristupe:

1. dozvoljava uključivanje trećeg i četvrtog momenta distribucije, odnosno meru asimetrije i spljoštenosti.

2. lako se izračunava na osnovu empirijske asimetrije i spljoštenosti iz standardizovanih prinosa $\left(\mathrm{z}_{\mathrm{t}}\right)$.

3. može se posmatrati kao aproksimacija VaR-a iz širokog spektra uslovljenih nenormalnih raspodela (Christoffersen, 2012).

Ostatak rada je organizovan na sledeći način. U prvom delu rada predstavljen je metodološki okvir istraživanja uz kratak opis testiranih VaR modela i tehnika za njihovu verifikaciju. Drugo poglavlje opisuje analizirane podatke i statističke karakteristike tržišta kapitala u Hrvatskoj. Rezultati istraživanja takođe su prikazani i objašnjeni u ovom delu. $\mathrm{Na}$ kraju rada dajemo zaključna razmatranja i preporuke za buduća istraživanja.

\section{METODOLOGIJA}

VaR meri verovatnoću nastanka potencijalnih gubitaka trenutnog portfolija za određeni interval poverenja tokom određenog vremenskog horizonta. Njegova jednostavnost leži u tome što se potencijalni rizik može sumirati u jednom broju (Jeremić et al., 2016).

Korišćenje Korniš-Fišerove ekspanzije je relativno jednostavan način hvatanja u koštac sa raspodelom prinosa finansijske aktive koja ne sledi normalnu distribuciju (Cornish \& Fisher, 1937). Takođe, ona omogućava optimizaciju portfolija sa sofisticiranijim merama rizika od varijanse prinosa, kao što su VaR ili očekivani gubitak u repu raspodele (engl. Expected tail loss, Shortfall probability, Conditional VaR).
U radovima Mendlbrota (1963), Fame (1965) i ostalih, nenormalnost je empirijski dokazana činjenica, kada su u pitanju raspodele prinosa finansijske aktive. Korniš-Fišerova ekspanzija nije jedini način za generisanje Gausovih slučajnih promenljivih moguće zamene su: Edgevorthova ekspanzija, ekspanzija Gram-Šarlijea, procesi sa skokovima, itd. (Alexander, 2008). U ovom radu fokus će biti na Korniš-Fišerovoj ekspanziji i njenom uključivanju u procenu izloženosti tržišnim rizicima. Prisustvo asimetrije (engl. skewness) i spljoštenosti (engl. kurtosis) utiče na percepciju i merenje rizika. KornišFišerova ekspanzija omogućava uspostavljanje jednostavne veze između parametara asimetrije i spljoštenosi i VaR procena. Dakle, primenićemo Korniš-Fišerovu aproksimaciju u formuli za izračunavanje linearnog VaR-a i ocenićemo verodostojnost tih procena. Takođe, rezultate ćemo porediti sa procenama standardnog VaR modela koji pretpostavlja normalnu raspodelu, kao što je JP RM VaR, zatim sa Studentovim t linearnim VaR-om koji su razvili Jeremić i Terzić (2014), na primeru srpskog tržišta kapitala i istorijskom simulacijom kao neparametarskim modelom.

U radu ćemo koristiti analitičko parametarski pristup za računanje VaR-a, odnosno linearni VaR sa pretpostavkama da promene u vrednosti portfolija tokom analiziranog vremenskog perioda imaju normalnu i nenormalnu raspodelu, kao i neparametarski model istorijske simulacije sa pokretnim okvirom od 500 dana. Testirani VaR modele računamo prema sledećim formulama:

1. Normalni linearni VaR

$$
\operatorname{VaR}_{\alpha}=\mathrm{F}^{-1}(1-\alpha) \sigma-\mu
$$

2. Student t linearni $\operatorname{VaR}^{1}$

$$
\text { Student } \operatorname{Var}_{\alpha, n}=\sqrt{n^{-1}(n-2)} t_{n}^{-1}(1-\alpha) \sigma-\mu
$$

3. Istorijska simulacija

$$
\operatorname{VaR}_{\alpha}=F^{-1}(\alpha)=X_{t}
$$

4. Cornish-Fisher VaR

$$
V a R_{\alpha}=\mathrm{CF}^{-1}(1-\alpha) \sigma-\mu
$$

gde je

$$
\begin{aligned}
C F_{\alpha}^{-1} & =F_{\alpha}^{-1}+\frac{\dot{\hat{\tau}}}{6}\left[\left(F_{\alpha}^{-1}\right)^{2}-1\right]+ \\
& +\frac{\hat{x}}{24}\left[\left(F_{\alpha}^{-1}\right)^{3}-3 F_{\alpha}^{-1}\right]-\frac{\hat{\tau}^{2}}{36}\left[2\left(F_{\alpha}^{-1}\right)^{3}-5 F_{\alpha}^{-1}\right]
\end{aligned}
$$

gde su:

$\hat{\hat{\tau}}$ mera asimetrije i $\hat{x}$ mera spljoštenosti standardizovanog prinosa, $\mathrm{z}$.

1 Metodologiju utvrđivanja Studentovog t linearnog VaR-a, kao i metodologiju za utvrđivanje vrednosti stepena slobode videti u Jeremić i Terzić (2014) 
Sledeći važan input prilikom računanja linearnog VaR modela je volatilnost. Standardnu devijaciju prinosa (volatilnost) modelovaćemo preko eksponencijalno ponderisanih pokretnih proseka (EWMA) i koristićemo je kod procene svih parametarskih VaR modela sa različitim pretpostavkama raspodele stopa prinosa. EWMA se može predstaviti sledećom formulom:

$$
\sigma_{n}^{2}=\lambda \sigma_{n-1}^{2}+(1-\lambda) u_{n-1}^{2}
$$

gde je $\sigma_{n-1}^{2}$ ocena varijanse u vremenskoj jedinici n, $u_{n-1}^{2}$ je kvadratna stopa prinosa. Koeficijent slabljenja jačine uticaja prethodnih vrednosti je označen sa $\lambda$, čiju ćemo vrednost uzeti da je $\lambda=0,94$.

U svrhu verifikacije i komparacije prezentiranih VaR modela koristićemo Kupikov (1995) i Kristofersenov (1998) backtest. ${ }^{2}$ Prvi test nam govori da li su izuzeci procenjenih vrednosti VaR-a u skladu sa stopom pokrivenosti, odnosno intervalom poverenja. Drugi test nam govori da li su VaR izuzeci vremenski nezavisni, pa se stoga ovaj backtest često naziva i test nezavisnosti.

\section{PODACI I ISTRAŽIVANJE}

Podaci o dnevnom kretanju vrednosti indeksa preuzeti su sa zvaničnog veb sajta Zagrebačke berze. Koristićemo dnevne kontinuelne stope prinosa blue chip indeksa CROBEX od 2005. do 2015. godine. Kontinuelna stopa prinosa je prirodni logaritam količnika tekuće i prethodne vrednosti indeksa:

$$
\mathrm{r}_{t}=100^{*}\left(\ln P_{t}-\ln P_{t-1}\right)=100^{*}\left(\ln P_{t} / \ln P_{t-1}\right)
$$

$\mathrm{Na}$ osnovu VaR modela definisanih u prvom delu rada odredićemo 1\% i 5\% dnevni VaR, što nam ukupno daje osam različitih modela rizika koji će biti predmet empirijske analize. Prvih 500 prinosa koristimo za procenu prve buduće vrednosti VaR-a, i tehnikom pokretnog okvira vršimo procene do 2015 godine. Ostatak serije (od 2007. godine) ćemo koristi u svrhe backtesting-a, odnosno validacije testiranih VaR modela za oba intervala poverenja.

Pre analize i dijagnostike uspešnosti VaR modela u proceni tržišnog rizika ukratko ćemo ispitati osnovne stilizovane činjenice prinosa CROBEX-a. Grafički prikaz kretanja vrednosti indeksa i njegovih dnevnih promena prikazan je na slici 1. Jasno je prikazan period svetske ekonomske krize, kada je došlo do naglog pada vrednosti indeksa, a samim tim i do grupisanja volatilnosti u klastere. $U$ periodu nakon krize dolazi do stabilizacije vrednosti indeksa i znatno manjeg kolebanja, ali daleko od povratka na vrednosti pre izbijanja krize.

U tabeli 1 su prikazani sumarni statistički podaci analizirane vremenske serije, kao i rezultati Jarque-Bera testa. Iako je ostvario negativnu vrednost, prosečan dnevni prinos CROBEX-a je blizak nuli i nije ga moguće statistički odbaciti 2 Za detaljnu backtesting metodologiju pogledati u Terzić (2014). (p-vrednost od 35,21\% je mnogo veća od nivoa značajnosti od 5\%). Standardna devijacija prinosa potpuno dominira nad srednjom vrednošću prinosa, u kratkim vremenskim periodima kao što je dnevni vremenski horizont. Nekondicionalna dnevna volatilnost je 1,25\%. CROBEX pokazuje spljoštenost u iznosu od 17,75, što ukazuje da je raspodela prinosa leptokurtična. Adekvatno razumevanje „debelih repova“ je od ključnog značaja prilikom modeliranja tržišnog rizika. Još jedna odlika vremenskih serija je prisustvo asimetrije. Zapravo, stope prinosa indeksa imaju negativnu zakošenost koja je reda veličine $-0,01$. Ipak, dodatni statistički testovi za nivo značajnosti od $5 \%$ pokazuju da mera asimetrije nije statistički značajno različita od 0 ( $\mathrm{p}$ vrednost u iznosu od $42,12 \%$ ), pa možemo zaključiti da prinosi CROBEX-a imaju simetričnu raspodelu. Na bazi sumarne statistike možemo zaključiti da vremenska serija nema oblik normalne raspodele prinosa, što smo potvrdili i Jarque-Bera testom, koji je odbacio nultu hipotezu o normalnoj raspodeli za nivo značajnosti od 5\%. Maksimalni dnevni prinos u posmatranom vremenskom intervalu iznosio je $14,78 \%$, dok je minimalna vrednost bila $-10,76 \%$. Tabela 1 prikazuje prvi i treći kvartal (Q1 i Q3) koji nam govore da se $50 \%$ posmatranih vrednosti iz uzorka nalazi u intervalu između Q1 i Q3. Njihova upotreba u analizi vremenskih serija je značajna, jer nam omogućava da brzo ispitamo autlejere u podacima.

Dobijene procene i rezultati validacije dnevnih VaR modela (IS 500, JP RM, Student $t$ VaR i CFVaR) na različitim nivoima značajnosti (1\% i $5 \%$ ) su prikazani u tabelama 2 do 5 . U razmatranje smo uzeli rezultate racio testova verodostojnosti u svrhu backtesting-a za bezuslovnu pokrivenost, osobinu nezavisnosti i uslovnu pokrivenost.

Kao što se može videti iz tabela 2 do 5 , zadovoljavajući rezultat u pogledu Kupikovog testa uslovne pokrivenosti, Christoffersen-ovog testa nezavisnosti i Christoffersen-ovog testa zajedničke uslovne pokrivenosti je zabeležen za $5 \%$ dnevni Korniš-Fišerov VaR. Drugim rečima, navedeni model je prošao tri backtest-a i sa velikom pouzdanošću izmerio tržišni rizik CROBEX indeksa. Vrlo loš učinak zabeležili su modeli istorijske simulacije, JPM RM VaR i t VaR za oba intervala poverenja od 95\% i 99\%. Iako modeli istorijske simulacije i Risk Metric VaR-a zadovoljavaju Kupikov uslov bezuslovne pokrivenosti za interval poverenja od $95 \%$, očigledno je grupisanje izuzetaka od VaR-a u klastere, što svakako vodi potcenjivanju rizika od stvarne izloženosti. Studentov t VaR takođe ostvaruje loše performanse, Kupikov backtest je zadovoljen samo u slučaju $1 \%$ dnevnog VaR-a, dok za nivo značajnosti od $5 \%$ nije prošao nijedan model validacije. Rezultate za $t$ linearni VaR treba uzeti sa određenom dozom rezerve u smislu da je korišćen EWMA model za predviđanje volatilnosti, koja je kasnije implementirana u VaR formulu. Empirijski je više puta dokazano da je modeliranje volatilnosti uz pomoć modela iz GARCH familije superiornije u odnosu na EWMA model (Alexander, 2008), što bi verovatno poboljšalo uspešnost ovog VaR modela, ali je za dokazivanje ove pretpostavke neophodno sprovesti dodatno istraživanje. Na osnovu svega 
navedenog možemo zaključiti da standardni VaR modeli, zasnovani na normalnoj raspodeli (J. P. Morgan Risk Metric $V a R$ ) ili empirijskoj distribuciji prinosa (Istorijska simulacija 500), nisu pogodni za pouzdano merenje izloženosti tržišnom riziku na hrvatskom tržištu akcija. Takođe smo obezbedili nove dokaze da su modifikovani VaR modeli zasnovani na nekoj od nenormalnih raspodela znatno pogodniji za procenu rizika na hrvatskom tržištu akcija. Istraživanje je pokazalo da Korniš-Fišerova ekstenzija značajno poboljšava VaR procene i pokazuje superiornost u odnosu na ostale analizirane modele.

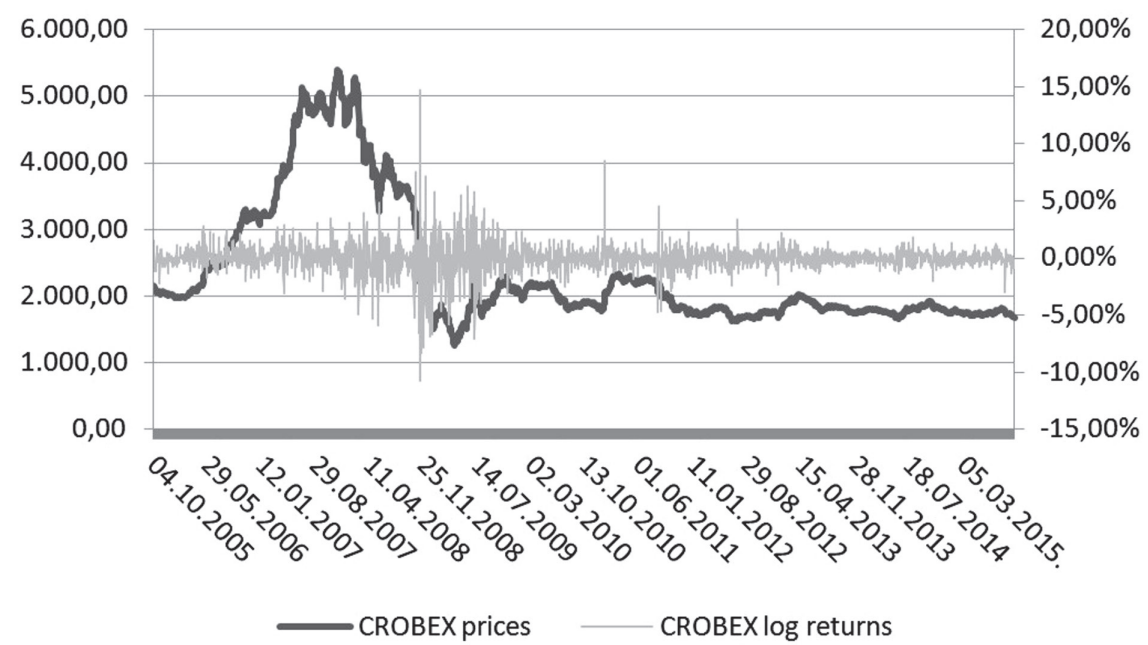

Slika 1. Vrednost indeksa i stope prinosa u periodu od 2005. do 2015. godine

Tabela 1. Sumarna statistika prinosa CROBEX indeksa od 2005. do 2015. godine

\begin{tabular}{ccccc}
\hline \multicolumn{2}{c}{ Deskriptivna statistika } & \multicolumn{3}{c}{ Testovi značajnosti } \\
\hline AVERAGE: & $-0,01 \%$ & 0 & P-Value & SIG? \\
\hline STD DEV: & $1,25 \%$ & - & $35,21 \%$ & FALSE \\
\hline SKEW: & $-0,01$ & 0 & $42,12 \%$ & FALSE \\
\hline KURTOSIS: & 17,75 & 0 & $0 \%$ & TRUE \\
\hline MEDIAN: & $0,00 \%$ & & & \\
\hline MIN: & $-10,76 \%$ & & & \\
\hline MAX: & $14,78 \%$ & & & \\
\hline Q 1: & $-0,45 \%$ & & & Pass? \\
\hline Q 3: & $0,48 \%$ & & P-Value & FALSE \\
\hline Normality Test & Score & C.V. & & \\
\hline Jarque-Bera & 32936,27 & 5,99 & &
\end{tabular}

Tabela 2. Backtesting modela istorijske simulacije za period od 2007. do 2015. godine

\begin{tabular}{ccc}
\hline \multirow{2}{*}{ Backtest } & \multicolumn{2}{c}{ Istorijska simulacija RW 500 } \\
\cline { 2 - 3 } & $1 \%$ & $5 \%$ \\
\hline $\mathrm{T}_{0}$ & 1988 & 1900 \\
\hline $\mathrm{T}_{1}$ & 30 & 118 \\
\hline $\mathrm{T}_{00}$ & 1962 & 1809 \\
\hline $\mathrm{T}_{01}$ & 26 & 91 \\
\hline $\mathrm{T}_{10}$ & 26 & 91 \\
\hline $\mathrm{T}_{11}$ & 4 & 27 \\
\hline$\hat{p}$ & $1.49 \%$ & $5.85 \%$ \\
\hline $\mathrm{L}(\hat{p})$ & $1.72 \mathrm{E}-68$ & $6.07 \mathrm{E}-196$ \\
\hline $\mathrm{L}_{\mathrm{p}}(\mathrm{p})$ & $2.10 \mathrm{E}-69$ & $1.42 \mathrm{E}-196$ \\
\hline$\hat{p}_{01}$ & $1.31 \%$ & $4.79 \%$ \\
\hline$\hat{p}_{11}$ & $13.33 \%$ & $22.88 \%$ \\
\hline $\left.\mathrm{L}_{(} \hat{p}_{1}\right)$ & $4.98 \mathrm{E}-66$ & $6.09 \mathrm{E}-187$ \\
\hline $\mathrm{LR}_{\mathrm{uc}}$ & 4.1986701 & 2.8998913 \\
\hline $\mathrm{LR}_{\text {ind }}$ & 11.339773 & 41.454774 \\
\hline $\mathrm{LR}_{\mathrm{cc}}$ & 15.538443 & 44.354666 \\
\hline $\mathrm{LR}_{\mathrm{uc}}$ & VaR Reject & VaR Accept \\
\hline $\mathrm{LR}_{\text {ind }}$ & VaR Reject & VaR Reject \\
\hline $\mathrm{LR}_{\mathrm{cc}}$ & VaR Reject & VaR Reject \\
\hline
\end{tabular}

Izvor: Kalkulacije autora
Tabela 3. Backtesting JPM RM VaR modela za period od 2007. do 2015. godine

\begin{tabular}{ccc}
\hline \multirow{2}{*}{ Backtest } & \multicolumn{2}{c}{ JPM RM VaR } \\
\cline { 2 - 3 } & $1 \%$ & $5 \%$ \\
\hline $\mathrm{T}_{0}$ & 1976 & 1902 \\
\hline $\mathrm{T}_{1}$ & 42 & 116 \\
\hline $\mathrm{T}_{00}$ & 1938 & 1802 \\
\hline $\mathrm{T}_{01}$ & 38 & 101 \\
\hline $\mathrm{T}_{10}$ & 38 & 100 \\
\hline $\mathrm{T}_{11}$ & 4 & 15 \\
\hline$\hat{p}$ & $2.08 \%$ & $5.75 \%$ \\
\hline $\mathrm{L}(\hat{p})$ & $2.09 \mathrm{E}-89$ & $1.60 \mathrm{E}-193$ \\
\hline $\mathrm{L}(\mathrm{p})$ & $2.37 \mathrm{E}-93$ & $5.14 \mathrm{E}-194$ \\
\hline$\hat{p}_{01}$ & $1.92 \%$ & $5.31 \%$ \\
\hline$\hat{p}_{11}$ & $9.52 \%$ & $12.93 \%$ \\
\hline $\left.\mathrm{L}_{\mathrm{p}}\right)$ & $5.15 \mathrm{E}-88$ & $1.57 \mathrm{E}-191$ \\
\hline $\mathrm{LR}_{\mathrm{uc}}$ & 18.169307 & 2.2740295 \\
\hline $\mathrm{LR}_{\text {ind }}$ & 6.4075476 & 9.1679004 \\
\hline $\mathrm{LR}_{\mathrm{cc}}$ & 24.576855 & 11.44193 \\
\hline $\mathrm{LR}_{\mathrm{uc}}$ & VaR Reject & VaR Accept \\
\hline $\mathrm{LR}_{\text {ind }}$ & VaR Reject & VaR Reject \\
\hline $\mathrm{LR}_{\mathrm{cc}}$ & VaR Reject & VaR Reject \\
\hline $\mathrm{Kak}_{\mathrm{n}}$ & &
\end{tabular}

Izvor: Kalkulacije autor 
Tabela 4. Backtesting JPM RM Student t VaR modela za period od 2007. do 2015. godine

\begin{tabular}{ccc}
\hline \multirow{2}{*}{ Backtest } & \multicolumn{2}{c}{ JPM RM Studentov t VaR $(\mathrm{df}=3,05)$} \\
\cline { 2 - 3 } & $1 \%$ & $5 \%$ \\
\hline $\mathrm{T}_{0}$ & 1990 & 1847 \\
\hline $\mathrm{T}_{1}$ & 28 & 171 \\
\hline $\mathrm{T}_{00}$ & 1965 & 1701 \\
\hline $\mathrm{T}_{01}$ & 25 & 147 \\
\hline $\mathrm{T}_{10}$ & 25 & 146 \\
\hline $\mathrm{T}_{11}$ & 3 & 24 \\
\hline$\hat{p}$ & $1.39 \%$ & $8.47 \%$ \\
\hline $\mathrm{L}(\hat{p})$ & $8.07 \mathrm{E}-65$ & $4.74 \mathrm{E}-255$ \\
\hline $\left.\mathrm{L}_{\mathrm{p}}\right)$ & $2.06 \mathrm{E}-65$ & $2.40 \mathrm{E}-264$ \\
\hline$\hat{p}_{01}$ & $1.26 \%$ & $7.96 \%$ \\
\hline$\hat{p}_{11}$ & $10.71 \%$ & $14.04 \%$ \\
\hline $\mathrm{L}_{p_{1}}$ & $4.88 \mathrm{E}-59$ & $1.27 \mathrm{E}-253$ \\
\hline $\mathrm{LR}_{\mathrm{uc}}$ & 2.7313493 & 42.811579 \\
\hline $\mathrm{LR}_{\text {ind }}$ & 26.623207 & 6.5702726 \\
\hline $\mathrm{LR}_{\mathrm{cc}}$ & 29.354556 & 49.381852 \\
\hline $\mathrm{LR}_{\mathrm{uc}}$ & VaR Accept & VaR Reject \\
\hline $\mathrm{LR}_{\text {ind }}$ & VaR Reject & VaR Reject \\
\hline $\mathrm{LR}_{\mathrm{cc}}$ & VaR Reject & VaR Reject \\
\hline
\end{tabular}

Izvor: Kalkulacije autora

\section{ZAKLJUČAK}

Jedan od najvećih problema, a ujedno i izazova, sa kojima se suočavaju finansijske institucije je kako upravljati i meriti izloženost tržišnim rizicima u njihovim portfeljima. Prema Bazelu II banke moraju da mere rizik pomoću VaR modela za interval poverenja od $99 \%$. Međutim, regulativa nije precizirala način za izračunavanje VaR-a, tako da je bankama dopušteno da primenjuju interne modele. Najjednostavniji način da utvrde VaR je pretpostavka da prinosi portfolija imaju normalnu distribuciju ili putem pristupa istorijske simulacije. Upravo su ti modeli najčešće primenjivani u praksi. Nažalost, nedavna kriza je pokazala da ovi modeli ne mogu da predvide i spreče bankrotstvo. Zato smo u radu razvili Korniš-Fišerovu (CFVaR) aproksimaciju za utvrđivanje VaR-a koja razmatra raspodele koje nisu normalne. Takođe smo izvršili empirijski backtesting i komparaciju CFVaR procena sa nekim od klasičnih $\mathrm{VaR}$ modela. Istraživanje je sprovedeno na primeru hrvatskog blue chip akcijskog indeksa CROBEX u periodu od 2005. do 2015. godine. Kako bismo ocenili uspešnost VaR modela, sproveli smo različite vrste backtest-ova. Backtestovi Kupika i Kristofersena ukazuju da klasični VaR modeli u značajnoj meri potcenjuju izloženost tržišnom riziku na različitim intervalima poverenja, dok za isti posmatrani period razvijeni savremeni VaR model (CFVaR) daje zadovoljavajuće procene tržišnog rizika. Dobijene procene i rezultati treba da posluže svim učesnicima na finansijskim tržištima u razvoju kao korisne smernice za unapređenje sistema upravljanja i merenja rizika.
Tabela 5. Backtesting CF VaR modela za period od 2007. do 2015. godine

\begin{tabular}{|c|c|c|}
\hline \multirow{2}{*}{ Backtest } & \multicolumn{2}{|c|}{ Korniš-Fišerov VaR } \\
\hline & $1 \%$ & $5 \%$ \\
\hline $\mathrm{T}_{0}$ & 1991 & 1925 \\
\hline $\mathrm{T}_{1}$ & 27 & 93 \\
\hline $\mathrm{T}_{00}$ & 1966 & 1840 \\
\hline $\mathrm{T}_{01}$ & 25 & 85 \\
\hline $\mathrm{T}_{10}$ & 25 & 85 \\
\hline $\mathrm{T}_{11}$ & 2 & 8 \\
\hline$\hat{p}$ & $1,34 \%$ & $4,61 \%$ \\
\hline $\mathrm{L}(\hat{p})$ & $5,85 \mathrm{E}-63$ & $1,85 \mathrm{E}-164$ \\
\hline $\mathrm{L}(\mathrm{p})$ & $2,04 \mathrm{E}-63$ & $1,32 \mathrm{E}-164$ \\
\hline$\hat{p}_{01}$ & $1,26 \%$ & $4,42 \%$ \\
\hline$\hat{p}_{11}$ & $7,41 \%$ & $8,60 \%$ \\
\hline $\mathrm{L}\left(\hat{p}_{1}\right)$ & $4,82 \mathrm{E}-59$ & $7,81 \mathrm{E}-164$ \\
\hline $\mathrm{LR}_{\mathrm{uc}}$ & 2,10513 & 0,667849 \\
\hline $\mathrm{LR}_{\text {ind }}$ & 18,03391 & 2,880454 \\
\hline $\mathrm{LR}_{\mathrm{cc}}$ & 20,13904 & 3,548303 \\
\hline $\mathrm{LR}_{\mathrm{uc}}$ & VaR Accept & VaR Accept \\
\hline $\mathrm{LR}_{\text {ind }}$ & VaR Reject & VaR Accept \\
\hline $\mathrm{LR}_{\mathrm{cc}}$ & VaR Reject & VaR Accept \\
\hline
\end{tabular}

Izvor: Kalkulacije autora

\section{LITERATURA}

Alexander, C. (2008). Value at Risk Models. Chichester: John Wiley \& Sons.

Christoffersen, P. (1998). Evaluating Interval Forecasts. International Economic Review, 39(4), 841-862.

Christoffersen, P. (2012). Elements of financial risk management. Waltham: Academic Press.

Cornish, E., \& Fisher, R. (1937). Moments and Cumulants in the Specification of Distributions. Revue de l'Institut International de Statistiques, 5, 307-320.

Fama, E. (1965). The behavior of stock market pricess. Journal of Business, 38(1), 34-105.

Jeremić, Z., \& Terzić, I. (2014). Empirical estimation and comparison of normal and Student-t linear VaR on the Belgrade Stock Exchange. Sinteza 2014: Uticaj interneta na poslovanje u Srbiji i svetu, 25-26 April 2014 (pp. 298-302). Beograd: Univerzitet Singidunum. doi:10.15308/sinteza-2014-298-302

Jeremić, Z., Terzić, I., \& Milojević, M. (2016). Value at Risk estimation and validation in the Serbian capital market in the period 2005-2015, Bankarstvo, 45(1), 15-42.

Kupiec, P.H. (1995). Techniques for verifying the accuracy of risk measurement models. Journal of Derivatives, 2, 73-84.

Mandelbrot, B. (1963). The variation of certain speculative prices. Journal of Business, 26(2), 394-419.

Terzić, I. (2014). Savremene metode merenja rizika na tržištu kapitala u Srbiji. Beograd: Univerzitet Singidunum.

Zagrebačka burza. (2016). Index CROBEX. Preuzeto 20. Septembra 2016. sa: http://zse.hr/default.aspx?id=44101\&index=CROBEX 


\section{EVALUATION OF THE CORNISH-FISHER VAR MODEL IN CAPITAL MARKET IN CROATIA FROM 2005 TO 2016}

\section{Abstract:}

In the last two decades VaR has become a benchmark for assessing market risk in the financial industry. Athough different approaches to assessing value at risk have been developed, financial institutions are still relying on standard VaR approaches, like historical simulation, variance-covariance model and Monte carlo simulation. The last crisis indicated that those models could not have predicted the black swans on the financial market with high certainty. Therefore, the purpose of this paper is to introduce Comish-Fisher (CFVaR) approximation for determining VaR i empirically perform backtesting and the comparison of CFVaR assessments using some of the stadard VaR approaches. The research was conducted on the example of the Croatian capital market from 2005 to 2015. Kupik and Cristofersen's backtests indicate that standard VaR models significantly underestimate the exposure to market risk, whereas CFVaR provides satisfying assessments of market risk for the same period. The research results are supposed to serve to all the participants in the financial market as useful guidelines for the improvement of risk management system in the contemporary business conditions.

\section{Keywords:}

market risk,

historical simulation, linear $\mathrm{VaR}$,

Crobex,

Comish-Fisher VaR 